\title{
Research on Faculty Performance Appraisal of Maritime Vocational Colleges
}

\author{
Ying Lian \\ Tianjin Maritime College, Tianjin 300350, China
}

\begin{abstract}
With the development of scientific management methodology, the faculty performance appraisal of maritime vocational colleges has been a hot topic. Evaluation of faculty performance is a multicriteria decision making problem. Best faculty members are the assets of an educational organization for increasing the quality education as well as for the popularity of that organization. So the faculty performance appraisal is very important in maritime vocational education to enrich their knowledge and evaluation of each individual's contribution to the organization. We propose a novel methodology based on Analytic Hierarchy Process and Technique for Order Preference by Similarity to Ideal Solution to evaluate the performance of staff. The experimental analysis illustrates the effectiveness of our proposed approach. The proposed model yields the ranking of the four faculty members for evaluating their performances.
\end{abstract}

KEYWORD: Maritime Vocational Colleges; Faculty Performance Appraisal; Decision Analysis; TOPSIS

\section{INTRODUCTION}

\subsection{Background Analysis}

Education system especially maritime vocational colleges' education contributes a major role to develop the nation. In an academic institution Teachers and Students are two main pillars and without these two an academic organization can never be survived. Teachers are the most important assets of an educational organization and good teachers provide the good quality education among the students. It means that teachers' performance evaluation has become one of the most important activities not only for the long run of an organization but for the development of the society.

Fuzzy analytic hierarchy process to evaluate the best technical institutions develop tolerate ambiguity and uncertainty of human judgment [1]. To improve the lack of recruitment process and reduce the personal management level and the novel method of fuzzy logical senses, Chen [2] trying to determine the proper characteristics and key professional skills through statistical information. P. Kousalya and et.al. take the use of multi criteria decision-making methods for ranking alternatives that curb student absenteeism in maritime vocational colleges [3].

\subsection{Our approach: an overview}

In this paper, faculty performance appraisal of maritime vocational colleges is presented. The proposed approach is based on two-step AHP and TOPSIS methodology for selecting the best teaching associate which is more powerful than traditional methods. Several students gave their opinions for teachers depending upon different criteria.).

\section{GENERAL CONCEPTS OF AHP/TOPSIS}

\subsection{Analytic Hierarchy Process}

The pair-wise comparison method and the hierarchical model were developed in 1980 by T.L.Saaty in the context of the Analytical Hierarchy Process (AHP) $[1,2]$. It is the best and the most widely used indicator method. Analytic hierarchy process (ahp) is a kind of decision-making method, including constructing multiple selection criteria hierarchy, to assess the relative importance of these standards, the standard for each alternative comparison, determine the overall ranking [3] of alternatives. AHP helps to capture the subjective and objective evaluation measures, provide a useful mechanism to check the consistency of the evaluation measures and proposal team to reduce bias decision. Some of its applications include technology choice, vendor selection of a 
telecommunications system, project selection, budget allocation. The steps for implementing the AHP process are illustrated as follows: (1) Define the Objectives, (2) Identify the Criteria/Attributes, (3) Choose the Alternatives, (4) Establish the Hierarchy, (5) Design Questionnaire and survey, (6) Construct the Pairwise Comparison matrices. In the proposed model, AHP hierarchy for best teacher selection through student's feedback report is shown in Fig. 1.

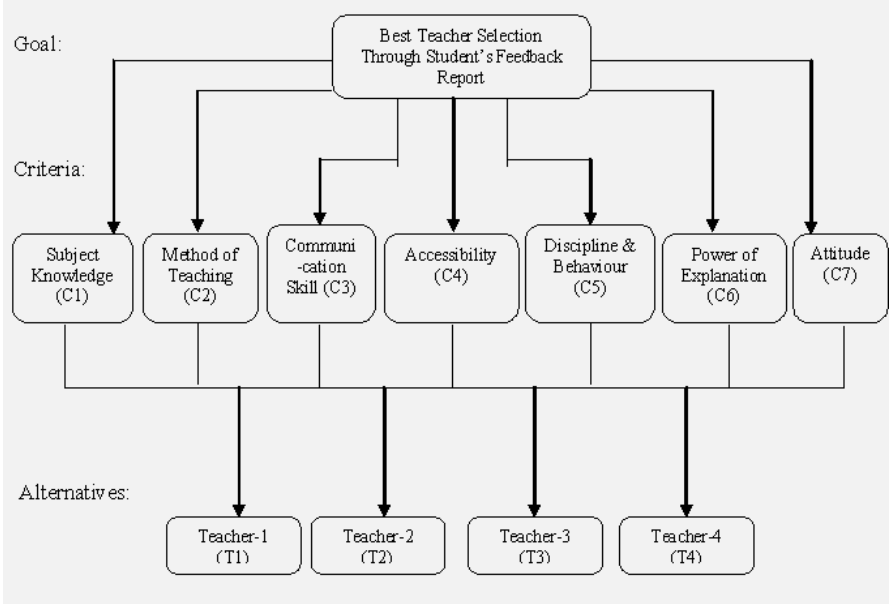

Figure 1. Hierarchy of Best Teacher Selection

\subsection{TOPSIS}

TOPSIS, known as one of the most classical MCDM methods, was first developed by Hwang and Yoon, is based on the idea that the chosen alternative should have the shortest distance from the Positive Ideal Solution (PIS) and on the other side the farthest distance of the Negative Ideal Solution (NIS). The Positive Ideal Solution maximizes the benefit criteria and minimizes the cost criteria, whereas the Negative Ideal Solution maximizes the cost criteria and minimizes the benefit criteria. In the process of TOPSIS, the performance ratings and the weights of the criteria are given as exact values. Abo-sinna and Amer extend TOPSIS approach to solve multiobjective nonlinear programming problems. Jahanshahloo et al. [4] extends the concept of TOPSIS to develop a methodology for solving multicriteria decision-making problems with interval data. The steps of TOPSIS model are as follows: (1) Calculate the normalized decision matrix, (2) Calculate the weighted normalized decision matrix, (3) Determine the Positive Ideal Solution and Negative Ideal Solution, (4) Calculate the separation measures for each alternative from the positive and negative ideal solution, (5) Calculate the relative closeness to the ideal solution for each alternative, (6) Rank the preference order.

\section{GENERAL STEPS OF PROPOSED METHOD}

\subsection{Overview}

In this paper we use two step methods consist of AHP and TOPSIS. In first step AHP is used for calculating the weights of the attributes or criteria as well as the overall weights of the candidates in each attribute. In second step these weights are considered and used in TOPSIS process. Then TOPSIS is applied for the evaluation problem and the result shows the preference order of the teachers in an educational organization. This methodology levels can be discussed clearly.

\subsection{AHP steps}

Step1: Selection of Experts

Step2: Identify the Attributes/Criteria

Step3: Identify the Alternatives

Step4: Design the Hierarchy

Step5: Establish the pair-wise comparison of the Criteria.

Step6: Calculate the Eigen value and Eigen vector

Step7: Perform the Consistency Test

Step8: Compute the weights of the Criteria

Step9: Establish the pair-wise comparison of the Alternatives with respect to each Criteria.

Step10: Calculate the Eigen value and Eigen vector for each of them.

Step11: Perform the Consistency Test

Step12: Compute the weights of the Alternatives for each Criteria

Step13: Calculate the Geometric Mean of the weights calculated by Experts

Step14: Calculate the Eigen value and Eigen vector

Step15: Perform the Consistency Test

Step16: Compute the overall weights of the Alternatives.

\subsection{TOPSIS steps}

Step17: Start TOPSIS procedure using the weights calculated using AHP.

Step18: Calculate negative and positive ideal solutions \& separation measures.

Step19: Rank the preference candidate in descending order.

\section{EXPERIMENTAL ANALYSIS}

Students give their own remarks for each teacher for each criterion which is shown in the figure2. According our two step methodology the model is followed the following steps: Start of AHP method Step-1: From the figure. taking the pair wise comparison matrix A according to Saaty's scale mentioned in table-1 of Student- 1 for the criteria Subject Knowledge (C1) is as follows: 


\begin{tabular}{c|c|c|c|c|} 
Criteria-1 & T1 & T2 & T3 & T4 \\
\hline T1 & 1.00000 & 0.50000 & 2.00000 & 1.00000 \\
\hline T2 & 2.00000 & 1.00000 & 4.00000 & 3.00000 \\
\hline T3 & 0.50000 & 0.25000 & 1.00000 & 0.50000 \\
\hline T4 & 1.00000 & 0.33333 & 2.00000 & 1.00000 \\
\hline
\end{tabular}

Step-2: Calculate the column sum $\sum_{i} C_{i j}$ for each column in the next figure.

\begin{tabular}{c|c|c|c|c|} 
Criteria-1 & T1 & T2 & T3 & T4 \\
\hline T1 & 1.00000 & 0.50000 & 2.00000 & 1.00000 \\
\hline T2 & 2.00000 & 1.00000 & 4.00000 & 3.00000 \\
\hline T3 & 0.50000 & 0.25000 & 1.00000 & 0.50000 \\
\hline T4 & 1.00000 & 0.33333 & 2.00000 & 1.00000 \\
\hline Sum & 4.5000 & 2.0833 & 9.0000 & 5.5000
\end{tabular}

Step-3: Standardized each cell by $X_{i j}=\frac{C_{i j}}{\sum_{i} C_{i j}}$.

\begin{tabular}{c|c|c|c|c|} 
Criteria-1 & T1 & T2 & T3 & T4 \\
\hline T1 & 0.2222 & 0.2400 & 0.2222 & 0.1818 \\
\hline T2 & 0.4444 & 0.4800 & 0.4444 & 0.5455 \\
\hline T3 & 0.1111 & 0.1200 & 0.1111 & 0.0909 \\
\hline T4 & 0.2222 & 0.1600 & 0.2222 & 0.1818 \\
\hline
\end{tabular}

Step-4: Calculate row sum.

\begin{tabular}{c|c|c|c|c|c|c|}
\hline Criteria-1 & T1 & T2 & T3 & T4 & Sum & W \\
\hline T1 & 0.2222 & 0.2400 & 0.2222 & 0.1818 & 0.8663 & 0.2166 \\
\hline T2 & 0.4444 & 0.4800 & 0.4444 & 0.5455 & 1.9143 & 0.4786 \\
\hline T3 & 0.1111 & 0.1200 & 0.1111 & 0.0909 & 0.4331 & 0.1083 \\
\hline T4 & 0.2222 & 0.1600 & 0.2222 & 0.1818 & 0.7863 & 0.1966
\end{tabular}

Step-5: Calculate the priority vector by $V_{i}=A W_{i}$.

\begin{tabular}{c|c|c|c|c|c|c|} 
Criteria-1 & T1 & T2 & T3 & T4 & W & P.Vector \\
\hline T1 & 1.00000 & 0.50000 & 2.00000 & 1.00000 & 0.2166 & 0.8690 \\
\hline T2 & 2.00000 & 1.00000 & 4.00000 & 3.00000 & 0.4786 & 1.9345 \\
\hline T3 & 0.50000 & 0.25000 & 1.00000 & 0.50000 & 0.1083 & 0.4345 \\
\hline T4 & 1.00000 & 0.33333 & 2.00000 & 1.00000 & 0.1966 & 0.7892 \\
\hline Sum & 4.5000 & 2.0833 & 9.0000 & 5.5000 & 1.0000 & 4.0273 \\
\hline
\end{tabular}

Step-6: Calculate $\lambda_{i}=\frac{V_{i}}{W_{i}}$.

\begin{tabular}{|c|c|c|c|c|c|c|c|c|}
\hline Criteria-1 & T1 & $\mathrm{T} 2$ & T3 & T4 & w & P.Vector & Lamda & $\max$ \\
\hline Tl & 1.00000 & 0.50000 & 2.00000 & 1.00000 & 0.2166 & 0.8690 & 4.0126 & 4.0206 \\
\hline $\mathrm{T} 2$ & 2.00000 & 1.00000 & 4.00000 & 3.00000 & 0.4786 & 1.9345 & 4.0422 & \\
\hline T3 & 0.50000 & 0.25000 & 1.00000 & 0.50000 & 0.1083 & 0.4345 & 4.0126 & \\
\hline T4 & 1.00000 & 0.33333 & 2.00000 & 1.00000 & 0.1966 & 0.7892 & 4.0151 & \\
\hline Sum & 4.5000 & 2.0833 & 9.0000 & 5.5000 & 1.0000 & 4.0273 & & \\
\hline
\end{tabular}

Step-7 to9: Calculate Consistency Index (C.I)[5] and Consistency Ratio (C.R)[6]. This value of C.R is less than the allowable value of 0.10 . Therefore, the consistency of the judgment matrix is found to be within an acceptable tolerance. But if the consistency ratio is greater than 0.10 we need to revise the subjective judgment. Repeat Step-1 to Step- 7 for Student-2 to Student-10 and check the consistency ratio for every judgment matrix. Calculate the
Geometric mean of each cell of Student-1 to Student-10 and repeat Step -1 to Step -7 for calculating the overall weight for each teacher for the criteria Subject Knowledge (C1). The weight for each teacher against the criteria $\mathrm{C} 1$ is shown in Fig.2.

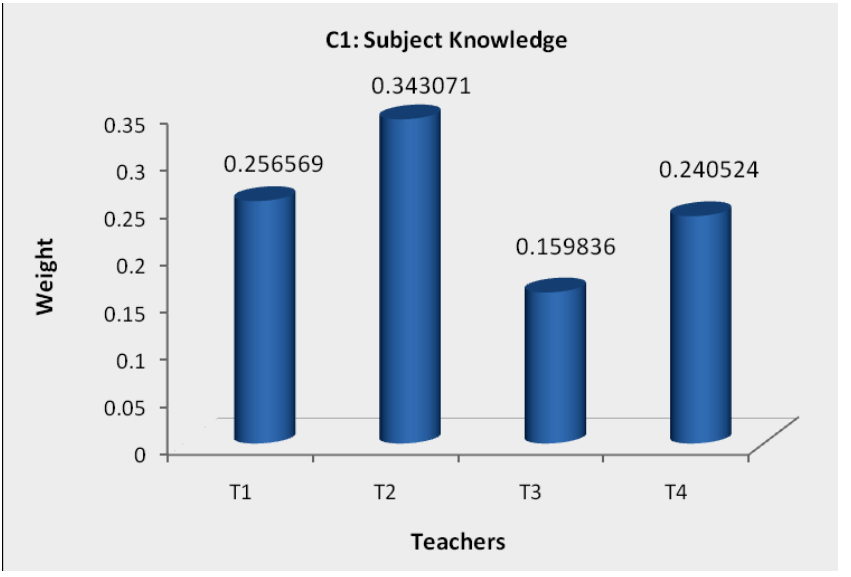

Figure 2. Weight of teachers for criteria C1

Step -10: Repeat Step-1 to Step-9 for each criterion and calculate the weights for each teacher according to each criterion and calculate the weight of each criterion by step- 1 to step- 7. The weights for each teacher against the other criteria C2, C3, C4, C5, C6 and C7 are calculated and we just show the result of $\mathrm{C} 2$ here for the limited space:

\section{C2: Method of Teaching}

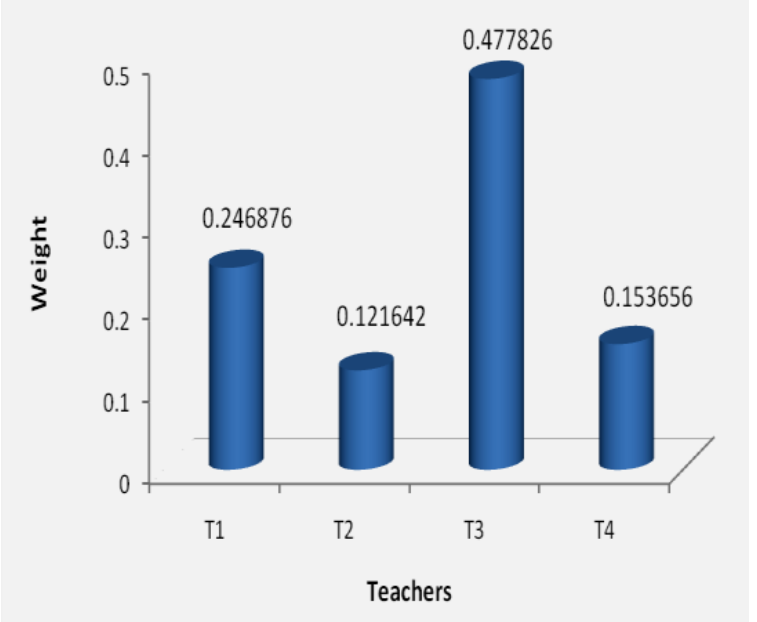

Figure 3. Weight of teachers for criteria C2

Step -11: Construct normalized decision matrix. Normalize scores or data as follows:

$$
r_{i j}=\frac{x_{i j}}{\left(\sum_{i} x_{i j}^{2}\right)^{1 / 2}}
$$

Step -12 to 13: Construct the weighted normalized decision matrix. Multiply each column of the 
normalized decision matrix by its associated weight. Determine the ideal and negative ideal solutions.

Step -14: Calculate the separation measures for each alternative. The separation from the ideal alternative is:

$$
S_{i}^{*}=\left[\sum_{j}\left(v_{j}^{*}-v_{i j}\right)^{2}\right]^{1 / 2}
$$

Similarly, the separation from the negative ideal alternative is:

$$
S_{i}^{\prime}=\left[\sum_{j}\left(v_{j}^{\prime}-v_{i j}\right)^{2}\right]^{1 / 2}
$$

The following figures show the statistical data of

\begin{tabular}{|c|c|c|c|c|c|c|c|c|c|}
\hline Teacher & $\mathrm{Cl}$ & $\mathrm{C} 2$ & $\mathrm{C} 3$ & $\mathrm{C} 4$ & C5 & C6 & C7 & SUM & $\mathrm{S}_{\mathrm{i}}^{*}$ \\
\hline $\mathrm{Tl}$ & 002686 & 0.006949 & 0.000746 & 0.00039 & 0.00038 & 0 & 0.000178 & 0.011329 & 0.106438 \\
\hline $\mathrm{T} 2$ & 0 & 0.016528 & 0 & 0 & 0 & 0.006475 & 0.000415 & 0.023418 & 0.153029 \\
\hline T3 & 01205 & 0 & 002562 & 0.000268 & 0.000171 & 0.003 & 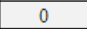 & 0.0 & 0.136543 \\
\hline T4 & 03774 & 0.01369 & 0.000921 & 0.001 & 0.000482 & 0.000622 & 0.000005 & 0.02 & 0.143206 \\
\hline Teach & $\mathrm{Cl}$ & c & $\mathrm{C} 3$ & $\mathrm{C}$ & C & C & C & SUM & $\mathrm{s}_{\mathrm{i}}^{\prime}$ \\
\hline Tl & 0.003358 & 0.002043 & 0.000543 & 0.000146 & 0.000006 & 0.006475 & 0.00005 & 0.012621 & 0.112343 \\
\hline T2 & 0.01205 & 0 & 0.002562 & 0.001014 & 0.000482 & 0 & 0 & 0.016108 & 0.126917 \\
\hline T3 & 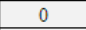 & 0.016528 & 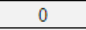 & 0.000239 & 0.000079 & 0.000421 & 0.000415 & 0.017682 & 0.132974 \\
\hline 17 & 0.002337 & 0.000134 & 0.000411 & 0 & 0 & 0.003083 & 0.000327 & 0.006292 & 0.079322 \\
\hline
\end{tabular}
the related experiment:

Step -15: Calculate the relative closeness to the ideal solution $C_{i}^{*}$ and the corresponding rank of the candidate. The overall ranking for each teacher is presented in Fig. 5.

$$
C_{i}^{*}=\frac{S_{i}^{\prime}}{S_{i}^{*}+S_{i}^{\prime}}
$$

\begin{tabular}{c|c|c|} 
Teacher & Result & Rank \\
\hline T1 & 0.513495 & 1 \\
\hline T2 & 0.453362 & 3 \\
\hline T3 & 0.493379 & 2 \\
\hline T4 & 0.356459 & 4 \\
\hline
\end{tabular}

Figure 4. Relative closeness and rank of the teacher

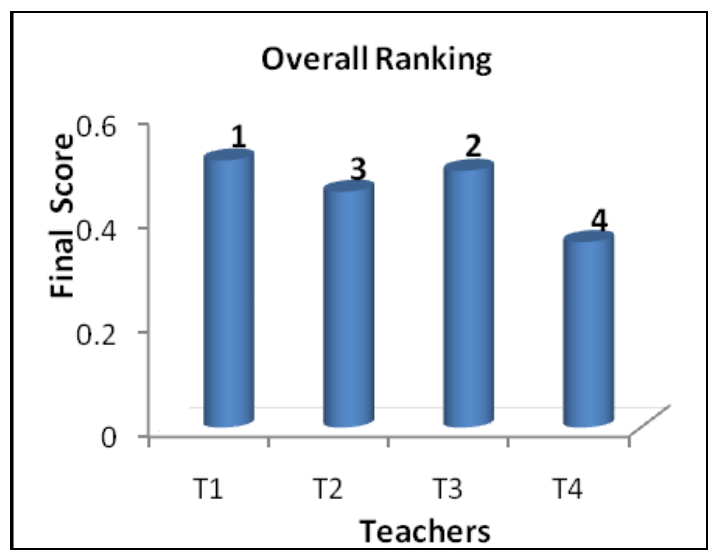

Figure 5. Overall Ranking of Teachers

\section{SUMMARY AND CONCLUSION}

This paper concludes that the teacher $\mathrm{T} 1$ is best in his performance and followed by teacher T3 and teacher T2. The overall performance of the teacher $\mathrm{T} 4$ is not good enough with respect to different criteria among all other teachers. It is notable that the subject knowledge of the teacher T2 is better than the teachers $\mathrm{T} 1 \& \mathrm{~T} 3$ and $\mathrm{T} 4$ is also better than $\mathrm{T} 3$. That means it can be also concluded that in spite of having sufficient knowledge of a teacher about his subject he/she may not be the best faculty member in his department. Finally this article introduces an approach that integrates AHP with TOPSIS algorithm to support faculty performance appraisal of maritime vocational college decisions. In the future, we plan to use some mathematical implementation to modify our method and use optimization knowledge [7-8] and related inequality method [9-11] to improve our method.

\section{REFERENCES}

[1] T. L. Saaty, The Analytic Hierarchy Process, McGrawHill, New York, 1980.

[2] T. L. Saaty,"Priority Setting in Complex Problems," IEEE Transactions on Engineering Management, Vol.30, No.3, pp.140- 155, 1983.

[3] Christos Douligeris \& Ian J. Pereira, "A Telecommunications Quality Study Using the Analytic Hierarchy Process," IEEE Journal on Selected Areas in Communications, Vol. 12, No. 2, 1994.

[4] F. Zahedi, "The analytic Hierarchy process-A survey of the method and its applications," Interfaces, Vol. 16, pp.343-350, 1977.

[5] V.S. Lai, R.P.Trueblood \& B.K.Wong "Software selection: a case study of the application of the analytical hierarchical process to the selection of a multimedia authoring system," Information \& Management, Vol. 25, No. 2, 1992.

[6] Maggie, C.Y.Tam, \& V.M. Rao Tummala, "An application of the AHP in vendor selection of a telecommunications system," Omega, Vol. 29, pp.171$182,2001$.

[7] Deb, Kalyanmoy. "Multi-objective optimization." Search methodologies. Springer US, 2014. 403-449.

[8] Drummond, LM Grana, F. M. P. Raupp, and B. F. Svaiter. "A quadratically convergent Newton method for vector optimization." Optimization 63.5 (2014): 661-677.

[9] $\mathrm{Xu}, \mathrm{Biao}$, et al. "On reverse Hilbert-type inequalities." Journal of Inequalities and Applications 2014.1 (2014): 198.

[10] Yang, Bicheng, and Qiang Chen. "A more accurate halfdiscrete reverse Hilbert-type inequality with a nonhomogeneous kernel." Journal of Inequalities and Applications 2014.1 (2014): 1-13.

[11] Yang, Bicheng. "A Multidimensional Discrete HilbertType Inequality." International Journal of Nonlinear Analysis and Applications 5.1 (2014): 80-88. 